\section{Severe pulmonary hypertension reversed by antibiotics in a patient with Whipple's disease}

H Riemer, R Hainz, Ch Stain, G Dekan, M Feldner-Busztin, P Schenk, Ch Müller, K Sertl, O C Burghuber

\begin{abstract}
The case is described of a 58 year old man with systemic Whipple's disease with pericardial and pleural effusions and severe pulmonary hypertension. After three months of antibiotic treatment there was a complete resolution, not only of the symptoms known to be associated with Whipple's disease (diarrhoea, arthralgia, pericardial and pleural effusions), but also of pulmonary hypertension.

(Thorax 1997;52:1014-1015)
\end{abstract}

Keywords: Whipple's disease, pulmonary hypertension, pleural effusion, pericardial effusion, Tropheryma whippelii.

Whipple's disease is characterised by weight loss, diarrhoea, arthralgia, and abdominal pain. ${ }^{1}$ Although the main manifestation of this disease is gastrointestinal, it is a systemic disorder and pulmonary involvement is a frequent but not well known finding. A chronic nonproductive cough, dyspnoea, and pleuritic chest pain have been reported more often than pleural effusion and nodular shadowing. ${ }^{23}$

Pulmonary hypertension associated with Whipple's disease has been reported previously in only two cases. ${ }^{45}$ We describe a case of systemic Whipple's disease with pericardial and pleural effusions and severe pulmonary hypertension in a 58 year old man in whom the pulmonary hypertension resolved completely after antibiotic therapy.

\section{Case report}

A 58 year old man was admitted with pericardial and pleural effusions and pulmonary hypertension of unknown origin. Three month before admission he had complained of diarrhoea and reported 6-10 bulky stools per day, a weight loss of $10 \mathrm{~kg}$, progressive dyspnoea, and a dry cough. Physical examination showed a cachectic man $(172 \mathrm{~cm}, 57.5 \mathrm{~kg})$ with brownish hyperpigmentation. Cardiac examination revealed normal first and second heart sounds with a pansystolic 3/6 murmur over the tricuspid valve. The lungs showed dullness to percussion and absence of breath sounds at both bases. Bilateral pretibial oedema was present. The laboratory haematological values re- vealed microcytic, hypochromic anaemia and blood chemical values indicated malabsorption (sodium $128 \mathrm{mmol} / 1$; potassium $3.8 \mathrm{mmol} / 1$; chloride $87 \mathrm{mmol} / \mathrm{l}$; calcium $1.97 \mathrm{mmol} / \mathrm{l}$; protein $54.7 \mathrm{~g} / \mathrm{l}$; albumin $27.5 \mathrm{~g} / \mathrm{l}$; cholesterol $93 \mathrm{mg} / 100 \mathrm{ml}$; alkaline phosphatase $212 \mathrm{U} / \mathrm{l}$ ).

Gastroduodenoscopic examination, performed because of the diarrhoea, weight loss and laboratory findings indicating malabsorption, showed that the duodenal mucosa was coated with yellow-white plaques. The histological tissue specimen showed periodic acid Schiff (PAS) positive macrophages in the lamina propria and electron microscopy demonstrated intracellular bacilli. Furthermore, the species-specific base sequence for Tropheryma whippelii, demonstrated by polymerase chain reaction (PCR) ${ }^{6}$ confirmed the diagnosis of Whipple's disease.

A chest radiograph revealed small bilateral pleural effusions. High resolution computed tomographic (HRCT) scans of the chest showed perihilar areas of ground glass opacities, thickening of the interlobular and intralobular septa predominantly in the periphery of both lungs, and bilateral pleural effusions in the posterior basal area of both lungs measuring approximately $2 \mathrm{~cm}$ in diameter.

A diagnostic thoracocentesis was performed and revealed an exudate. The Ziehl-Neelsen stain and cytological examination of the pleural fluid were non-diagnostic. However, in cells from pleural effusions Tropheryma whippelii specific amplification products were found by PCR.

Transthoracic echocardiography (TTE) showed a dilated right ventricle and atrium. The interventricular septum was flattened, indicating increased right ventricular pressure or volume overload. Contrast echocardiography showed no evidence of intracardiac right-to-left shunt. An anterior small pericardial separation between pericardium and epicardium of approximately $2 \mathrm{~cm}$ in diastole was found. Colour flow Doppler sonography revealed tricuspid regurgitation with a regurgitant jet encompassing more than two thirds of the right atrium. The measured velocity of the regurgitant jet was $3.8 \mathrm{~m} / \mathrm{s}$, from which the estimated systolic gradient was calculated to be $57 \mathrm{mmHg}$ using the modified Bernoulli equation $\left(\mathrm{P}=4 \mathrm{~V}^{2}\right)$. Thus, a right ventricular systolic pressure of at least $65 \mathrm{mmHg}$ was estimated.

A ventilation-perfusion scan of the lungs revealed a very low probability of pulmonary embolism, since a small matched defect in the posterior basal area of the right lung was seen corresponding to the small amount of pleural effusion. No segmental or subsegmental mismatch was identified. Pulmonary function data indicated a mild restrictive ventilatory pattern (table 1) and a reduction in the carbon monoxide transfer factor (TLCO). Blood gas analysis revealed normoxaemia at rest, deteriorating during exercise, again indicating diffusion impairment (table 2).

Tests for antinuclear antibodies and their subsets, rheumatoid factor and antineutrophil cytoplasmatic antibodies were negative as were all tests for HIV and other viral diseases. 
Table 1 Pulmonary function variables (before and three months after starting antibiotic therapy)

\begin{tabular}{lcllll}
\hline Variable & Before & & & \multicolumn{2}{l}{ After } \\
\cline { 2 - 3 } \cline { 5 - 6 } & Absolute & $\%$ predicted & & Absolute & \% predicted \\
\hline TLC (1) & 5.08 & $88 \%$ & 5.60 & $91 \%$ \\
VC (1) $_{\text {FEV }_{1}(1)}$ & 2.40 & $56 \%$ & 3.37 & $79 \%$ \\
FEV $_{1} \%$ VC & 7.50 & $44 \%$ & & 2.11 & $61 \%$ \\
TLCO & 3.91 & $43 \%$ & & $78 \%$ & $65 \%$ \\
\hline
\end{tabular}

$\mathrm{TLC}=$ total lung capacity; $\mathrm{VC}=$ vital capacity $\mathrm{FEV}_{1}=$ forced expiratory volume in one second $\mathrm{FEV}_{1} \% \mathrm{VC}=$ forced expiratory volume in one second as percentage of vital capacity; TLCO =

carbon monoxide transfer factor.

Table 2 Blood gas analysis (before and three months after starting antibiotic therapy)

\begin{tabular}{llllll}
\hline Blood gas & Rest & & \multicolumn{2}{l}{ Exercise } & \\
\cline { 2 - 3 } \cline { 5 - 6 } & Before & After & & Before & After \\
\hline $\mathrm{PaO}_{2}(\mathrm{mmHg})$ & 77 & 89 & & 68 & 93 \\
$\mathrm{PacO}_{2}(\mathrm{mmHg})$ & 32 & 37 & & 28 & 37 \\
$\mathrm{~A}-\mathrm{aDO}_{2}(\mathrm{mmHg})$ & 33 & 15 & & 46 & 12 \\
\hline
\end{tabular}

$\mathrm{PaO}_{2}=$ arterial oxygen tension; $\mathrm{PaCO}_{2}=$ arterial carbon dioxide tension, $\mathrm{A}-\mathrm{aDo}_{2}=$ alveolar arterial difference in $\mathrm{PO}_{2}$.

$1 \mathrm{kPa}=7.5 \mathrm{mmHg}$
Discussion

Although involvement of the lung as a site of this disease was reported in Whipple's first description in $1907,{ }^{1}$ it is now known that the lung and the pleura may be affected both before and after the development of diarrhoea. ${ }^{3}$

The finding of severe pulmonary hypertension in Whipple's disease, however, has been reported in only two cases in the literature, in one as a result of severe aortic insufficiency and in the other by chronic progressive aortic regurgitation. Endocarditis, caused by Tropheryma whippelii, was thought to be the cause. Evidence of pericardial and endocardial involvement in Whipple's disease has been reported previously. ${ }^{8}$ In our patient involvement of the pericardium was evident because of the pericardial effusion.

The pulmonary function parameters demonstrated a slight restrictive ventilatory pattern and a reduced carbon monoxide transfer factor, possibly caused by the small amounts of bilateral pleural effusions and the thickening of the alveolocapillary membrane as shown by HRCT scanning. Both the small bilateral pleural effusions and the thickening of the interlobular and intralobular septa caused only mild functional impairment and cannot explain the severity of this pulmonary hypertension.

The strongest evidence for a causal relationship between Whipple's disease and pulmonary hypertension in our patient, however, was the resolution of the pulmonary hypertension after antibiotic therapy. It is therefore reasonable to assume that pulmonary vascular involvement by Tropheryma whippelii was the cause of pulmonary hypertension in this case. improved duodenal mucosa and increased jejunal folds. A biopsy sample of the duodenal tissue showed fewer PAS positive macrophages than at the initial examination.

A CT scan of the chest revealed complete resolution of the bilateral pleural effusions, the ground glass opacities, and the thickening of the interlobular and intralobular septa. Transthoracic echocardiography showed a right ventricle and atrium of normal size with no pericardial effusion. The maximum velocity of the tricuspid regurgitant jet was $2.2 \mathrm{~m} / \mathrm{s}$, indicating a pulmonary artery pressure within normal limits.

The pulmonary function data at that time showed that the total lung capacity and the carbon monoxide transfer factor per lung area were normal (table 1). Blood gas analysis revealed normoxaemia at rest and during exercise (table 2).
Whipple GH. A hitherto undescribed disease characterised anatomically by deposits of fat and fatty acids in the
intestinal mesenteric lymphatic tissues. Bull fohns Hopkins Hosp 1907;18:382-91.

2 Enzinger FM, Helwig EB. Whipple's disease: a review of the literature and report of fifteen patients. Virchows Arch Pathol Anat 1963;336:238-69.

3 Symmons DPM, Sheperd AN, Boardman PL, Bacon PA Pulmonary manifestations of Whipple's disease. $Q \mathcal{F}$ Med

4 Bostwick DG, Bensch KG, Burke JS, Billingham ME, Miller DC, Smith JC. et al. Whipple's disease presenting as aortic insufficiency. N Engl F Med 1981;305:995-8.

5 Morrison DA, Gay RG, Feldshon D, Sampliner RE. Severe pulmonary hypertension in a patient with Whipple's disease. Am $\mathcal{F}$ Med 1985;79:263-7.

6 Relman DA, Schmidt TM, MacDermott RP, Falkow St. ease. N Engl f Med 1992;327:293-301.

7 Müller Ch, Stain Ch, Burghuber O. Tropheryma whippelii in effusion. Lancet 1993;341:701.

8 McAllister HA, Fenaglio JJ. Cardiac involvement in Whipple's disease. Circulation 1975;52:152-6. Identification of the uncultured bacillus of Whipple's disperipheral blood mononuclear cells and cells of pleural 